\title{
Educação profissional paulista e relações público-privadas na política curricular: Centro “Paula Souza” (1995-2018)*
}

\author{
Carmen Sylvia Vidigal Moraes' (D) \\ Elydimara Durso dos Reis' (D) \\ Felipe Alencarl (D)
}

\begin{abstract}
RESUMO
O trabalho objetiva analisar as relações entre o público e o privado nas políticas de educação profissional do estado de São Paulo e, mais especificamente, nas propostas de organização curricular do ensino técnico de nível médio desenvolvido no Centro Estadual de Educação Tecnológica Paula Souza, nos anos 1995-2018. O estudo utiliza fontes primárias (documentos governamentais e os produzidos na instituição) e secundárias (revisão bibliográfica). Observa-se, nesse período histórico de gestão neoliberal dos governos do Partido da Social Democracia Brasileira no estado, a crescente atuação de agentes privados na formulação, no monitoramento e na avaliação das políticas curriculares da instituição. Tal movimento caracteriza um processo peculiar de privatização endógena do ensino profissional no âmbito da rede pública estadual de educação.
\end{abstract}

\section{PALAVRAS-CHAVE}

educação profissional; política educacional paulista; proposta curricular; privatização da educação.

'Universidade de São Paulo, São Paulo, SP, Brasil.

*Este artigo resulta da pesquisa Política Educacional na Rede Estadual Paulista (1995 a 2018), financiada pela Fundação de Amparo à Pesquisa no Estado de São Paulo (FAPESP), n. 2018/09983-0), e coordenada por Márcia Aparecida Jacomini. 


\title{
TECHNICAL EDUCATION IN THE STATE OF SÃO PAULO AND PUBLIC-PRIVATE RELATIONS IN CURRICULUM POLICY: PAULA SOUZA CENTER (1995-2018)
}

\begin{abstract}
This work aims to analyze the relations between public and private in technical education policy-making in the state of São Paulo and, more specifically, concerning the proposals for organizing the curriculum of high school technical education offered by Paula Souza State Center for Technological Education between 1995 and 2018. This study uses primary (government documents and those produced in the institution) and secondary sources (literature review). During this historical period of neoliberal management by the Brazilian Social Democracy Party (Partido da Social Democracia Brasileira) governments in the state, private agents have been observed to play an increasing role in the formulation, monitoring, and evaluation of the institution's curriculum policies. This represents a peculiar process of endogenous privatization of technical education within the state public education system.
\end{abstract}

KEYWORDS

technical education; São Paulo state educational policies; curricular proposal; privatization of education.

\section{EDUCACIÓN PROFESIONAL EN EL ESTADO DE SÃO PAULO Y RELACIONES PÚBLICO-PRIVADAS EN LA POLÍTICA CURRICULAR: CENTRO PAULA SOUZA (1995-2018)}

\section{RESUMEN}

El trabajo tiene por objetivo analizar las relaciones entre lo público y lo privado en las políticas de educación profesional en el estado de São Paulo y, más específicamente, en las propuestas de organización curricular de la educación técnica secundaria desarrolladas en el Centro Estatal de Educación Tecnológica Paula Souza, entre los años 1995-2018. El estudio utiliza fuentes primarias (documentos gubernamentales y los producidos en la institución) y secundarias (revisión de la literatura). Se observa, en este período histórico de gestión neoliberal de los gobiernos del PSDB (Partido da Social Democracia Brasileira) en el estado, el creciente papel de los agentes privados en la formulación, monitoreo y evaluación de las políticas curriculares de la institución. Este movimiento caracteriza un peculiar proceso de privatización endógena de la formación profesional en la red de enseñanza pública estatal.

\section{PALABRAS CLAVE}

educación profesional; política educativa de São Paulo; propuesta curricular; privatización de la educación. 


\section{INTRODUÇÃO}

O Centro Estadual de Educação Tecnológica "Paula Souza” $\left(\mathrm{CPS}^{1}\right)$ iniciou suas atividades no ano de 1969 - vinculado à época, para fins administrativos, à Secretaria da Educação e, para medidas financeiras, à Secretaria da Fazenda com o objetivo de organizar os primeiros cursos superiores de tecnologia. Veio a incluir, no transcorrer dos anos, a oferta de educação profissional de nível médio, absorvendo unidades já existentes da rede estadual de ensino e construindo novas escolas técnicas de nível médio e superior em todas as regiões do estado de São Paulo (CPS, 2021).

Em 1976, o CPS foi transformado em autarquia de regime especial (condição dada apenas às universidades), incorporado à Universidade Estadual Paulista "Júlio de Mesquita Filho"(UNESP) por meio da lei n. 952/1976 e vinculado à Secretaria do Desenvolvimento Econômico do Estado de São Paulo (SDE), com os objetivos de "promover o crescimento sustentável, aprimorar os ensinos superior, técnico e de graduação tecnológica e estimular a inovação [...] com políticas públicas voltadas à geração de emprego e renda e ao aumento do empreendedorismo e da competitividade do setor produtivo" (CPS, 2021).

Está presente, hoje ${ }^{2}$, em 369 municípios e administra 223 Escolas Técnicas Estaduais (ETEC) e 74 Faculdades de Tecnologia (FATEC), com mais de $300 \mathrm{mil}$ alunos em cursos técnicos de nível médio e superiores tecnológicos. Nas ETEC, há mais de 228 mil estudantes nos ensinos técnico, médio e técnico integrado ao médio, em habilitações que incluem as modalidades presencial, semipresencial, online, de educação de jovens e adultos (EJA) e especialização técnica. São 212 cursos voltados a todos os setores produtivos públicos e privados. Já as Fatec atendem mais de 94 mil alunos matriculados em 86 cursos de graduação tecnológica, cursos de pós-graduação, atualização tecnológica e extensão.

O percurso de expansão do CPS, conforme Sacilotto (2016, p. 25), “acompanha a trajetória histórica da educação profissional brasileira" e torna-se o "instrumento e o recurso institucional da implementação da política pública de educação profissional e tecnologia no Estado de São Paulo".

Apesar das reformas introduzidas na educação básica durante o período da ditadura civil militar (lei n. 5.692/1971), que promoveram o empobrecimento dos currículos escolares e o fracasso na realização da pretendida formação técnica, as escolas das redes de ensino técnico continuaram a funcionar sem interferências, adquirindo uma qualidade diferenciada, propiciada em parte pelo caráter seletivo de acesso dos alunos por meio de vestibulares e, em parte, pela relativa autonomia de sua gestão. Manifesta-se, dessa forma, na especificidade histórica da sociedade brasileira, uma dualidade no ensino invertida: a escola pública regular, propedêutica, consiste na modalidade de maior acesso da população pobre, enquanto a escola

1 Há duas siglas utilizadas pela instituição: CPS e CEETEPS.

2 CPS. Sobre o Centro Paula Souza. Disponível em: https://www.cps.sp.gov.br/sobre-o-centro-paula-souza/. Acesso em: 11 dez. 2021. 
técnica pública de nível médio se torna seletiva, destinada a menor número de alunos (Moraes, 2006; 2017).

Desde a promulgação da Lei de Diretrizes e Bases da Educação Nacional n. 9.394/1996 (LDB/1996), o formato do ensino médio e suas atribuições foram alvos de disputa. Logo em seguida à aprovação da LDB, o governo de Fernando Henrique Cardoso (FHC) emite decreto 2.208/1997, que separou os ensinos médio e técnico e desescolarizou o ensino técnico, com o objetivo de desmontar o ensino médio profissional ofertado nas escolas técnicas federais e estaduais, considerado de alto custo. As propostas do Banco Internacional para Reconstrução e Desenvolvimento (BIRD) e Fundo Monetário Internacional (FMI) foram executadas pelos governos estaduais e federal. Opera-se uma reformulação conceitual e pedagógica exitosa desde a denominação "ensino profissional", que passa a ser "educação profissional", até o deslocamento da noção de qualificação, substituída pela de competência, com suas implicações graves nas propostas curriculares e, portanto, na relação com o conhecimento. Ao mesmo tempo, foram introduzidas medidas de reorganização das redes de ensino em seus aspectos físicos e administrativos, trazendo formas de padronização de importantes meios e processos como livros didáticos, propostas curriculares centralizadas e avaliações externas - medidas compreendidas como necessárias ao crescimento econômico, à modernização do país e à sua inclusão no rol das economias capitalistas mais desenvolvidas (Souza, 2013). Além de não ter provocado mudanças na precariedade do atendimento nas escolas, as reformas implicaram descaracterização e maior desqualificação do ensino médio.

No marco das políticas neoliberais, da Reforma do Estado, da denominada Nova Gestão Pública (Laval, 2004; Verger e Normand, 2015) e dos pressupostos políticos e filosóficos que informam as políticas educacionais de governos do Partido da Social Democracia Brasileira (PSDB) desde 1995 no estado de São Paulo, torna-se relevante pesquisar a política educacional paulista em período histórico amplo. Nela estão envolvidas diferentes dimensões das ações realizadas pela Secretaria de Educação $(\mathrm{SEE})^{3}$ e pela Secretaria de Desenvolvimento Econômico, Ciência, Tecnologia e Inovação do Estado de São Paulo, à qual se vincula o CPS, com vistas a examinar o movimento das políticas direcionadas à educação profissional técnica de nível médio e à formação continuada, na sua relação com as normativas e diretrizes do governo federal no período definido.

À luz da abordagem do ciclo de políticas, são considerados os contextos de influência e de produção do texto e da prática (Ball, Maguire e Braun, 2016). Nessa direção, são aqui apresentadas algumas reflexões para análise do processo de formação de relações público-privadas na organização administrativa e pedagógica do CPS, entre 1995 e 2018. Desenvolve-se, inicialmente, breve histórico da expansão do ensino profissional no estado de São Paulo, com ênfase nas principais mudanças legais e sua incidência na política para, em seguida, examinar-se a política curricular, com enfoque nas matrizes curriculares do curso de Administração, entendida

3 Cf. Resolução SE n. 18, de 2 de maio de 2019, a sigla da Secretaria da Educação $\mathrm{SEE}-\mathrm{SP}$ - passou a ser SEDUC-SP. 
como um meio de materialização da intervenção de agentes privados na educação profissional (Moraes e Alencar, 2020).

Para melhor compreender a "enorme trama de atores e situações que interagem na trajetória das políticas educativas" (Ball, 1989, p. 24), é importante contextualizá-las no conjunto de mudanças que invadem o cenário nacional e internacional, destacando, por sua vez, alguns momentos importantes da configuração institucional do CPS na sua relação com as políticas federais de organização da educação profissional.

No trabalho de campo, no que se refere às fontes primárias, foi feito levantamento da legislação educacional nacional e estadual, de indicadores sociais e educacionais e de documentos institucionais: propostas e projetos educativos produzidos e implementados no CPS e sua rede de escolas, os elaborados pelas secretarias e governo do estado. Quanto às fontes secundárias - localização e revisão da bibliografia relacionada à educação profissional na rede estadual e, especificamente, ao CPS - é importante observar o escasso número de estudos e pesquisas encontrado sobre as origens e o desenvolvimento da instituição e suas escolas profissionais ${ }^{4}$. Foram localizados apenas quatro trabalhos acadêmicos: uma monografia (publicada em 2017) e uma tese de doutorado (publicada em 2016) produzidas na Pós-Graduação em Educação da FE-UNICAMP e dois mestrados profissionais defendidos em 2020 na FATEC-CPS. Tais trabalhos, referenciados em ampla consulta documental, constituíram importantes referências na elaboração do texto.

\section{EDUCAÇÃO PROFISSIONAL NO ESTADO DE SÃO PAULO: ENTRE CONTENÇÃO E EXPANSÃO}

Desde a posse de Mário Covas, em 1995, até a saída de Geraldo Alckmin, em 2018, para a disputa presidencial, apenas o PSDB esteve à frente do governo paulista. Depois de Covas (falecido em 2001), alternaram-se Geraldo Alckmin/ Cláudio Lembo (2001-2006) e José Serra (2007-2010). Este foi o grande período de expansão do CPS.

Após o momento inicial de discussão e disposição declarada pelo governo Covas de reorganizar a instituição, "deter a criação de novos cursos e unidades", rever convênios e "tratamento trabalhista", enfrentando resistência de movimentos organizados por professores, funcionários e alunos em todo o período, as gestões

4 O levantamento foi realizado no Catálogo de Teses e Dissertações/Coordenação de Aperfeiçoamento de Pessoal de Nível Superior (CAPES), de acordo com os seguintes termos selecionados: Centro Paula Souza, política educacional e educação profissional no estado de São Paulo.

5 Trabalhadores do CPS enfrentaram oito anos sem reajuste salarial. Relatos dos gestores da época sinalizam o clima de descontentamento na instituição. Apenas em 2008 foi construído um plano de carreira e de contratação de funcionários e aumentos salariais (lei complementar n. 1.044/2008). Consultar Fiala (2016). 
posteriores do PSDB mudaram de posição, passando à ampliação da rede via expansão de unidades - ETEC e FATEC - por todo o Estado.

Entre 1997 e 2002, o CPS procurou melhorar a infraestrutura das unidades sem promover qualquer expansão. $\mathrm{O}$ ano de 2002 marca a introdução da educação profissional na agenda de políticas públicas do governo estadual (Sacilotto, 2016) e, diferentemente das expansões anteriores, que incorporavam escolas existentes e criavam poucas unidades, a expansão via criação de novas escolas caracterizará as gestões do PSDB.

Nos anos 1990, na nova configuração imposta ao Estado brasileiro, as mudanças de natureza na sua dimensão pública tendem, como avalia Cohn (2004), a transplantar para o seu interior a racionalidade do setor privado, substituindo critérios republicanos de gestão social por critérios privatistas, pautados pela racionalidade do custo/efetividade, que desconhece a dimensão dos direitos sociais.

Até a vigência do decreto federal 2.208/1997, o ensino técnico profissional era oferecido simultaneamente e de forma integrada ao ensino médio geral, nas redes de escolas técnicas federal e estaduais, de modo a atender à formação profissional nas áreas de serviço, indústria e agricultura. Para se adequar às determinações da LDB/1996 e do decreto federal, o governo do estado de São Paulo promoveu mudanças nas escolas estaduais, bloqueando matrículas nas séries iniciais dos cursos profissionalizantes, ao mesmo tempo em que determinou a separação entre ensino médio e ensino técnico.

As alterações na organização administrativa, pedagógica e didático-curricular introduzidas nas escolas técnicas do CPS, decorrentes da implantação do decreto federal 2.208/1997, estão associadas às interferências de organismos internacionais e nacionais, aos interesses de setores sociais da sociedade brasileira, à adoção da agenda neoliberal pelo governo FHC e à própria dinâmica da instituição mantenedora das escolas técnicas estaduais e dos sujeitos sociais que nela interagem. Podem ser resumidas em alguns pontos principais: desvinculação do ensino técnico do ensino médio; modularização dos cursos; reformulação dos currículos segundo o modelo das competências; reformulação dos modelos convencionais de aquisição de conhecimento; e sistematização de mecanismos de avaliação da qualidade de ensino (Koritiake, 2008; Sacilotto, 2016).

De acordo com o MEC, no documento Planejamento Estratégico 95/98, no caso dos cursos profissionalizantes, "o eixo das articulações se voltará para as instituições de formação profissional (Sistema Nacional de Aprendizagem Industrial - SENAI; Serviço Nacional de Aprendizagem Comercial - SENAC; Serviço Nacional de Aprendizagem Rural - SENAR; Serviço Social do Transporte e o Serviço Nacional de Aprendizagem do Transporte - SENAT e congêneres) e para o próprio setor produtivo" (Moraes, 2001). Integrando a agenda governamental neoliberal e alicerçado nas premissas da Teoria do Capital Humano, o decreto de reforma do ensino técnico prevê nesse aspecto, tal como no SENAI, que as escolas incluam nos conselhos de administração (Conselho de Direção e Conselho Consultivo) a participação de empresários da região onde se localizam, de modo que eles possam orientar seus rumos de acordo com as demandas das empresas locais.E, assim como o Senai, propõe ajustar as escolas ao mercado organizando os currículos 
de ensino, tendo como parâmetros perfil ocupacional e demandas (competências) do mercado de trabalho - e não mais "currículos montados a partir de disciplinas acadêmicas" (Oliveira, 1995), na expressão de um consultor do BIRD.

O decreto n. 2.208/1997 afirma, como um dos objetivos da reforma, acompanhar o avanço tecnológico de forma a atender as novas demandas do mercado, que exige "flexibilização, qualidade e produtividade". Na concepção da proposta, com vistas a conduzir ao permanente desenvolvimento das aptidões para a vida produtiva, o currículo do ensino técnico é estruturado por áreas e setores da economia e organizado, preferencialmente, sob a forma modular. Os módulos podem ser cursados em diferentes instituições e ter caráter de terminalidade para efeito de qualificação profissional, dando direito a certificados de competência. A frequência e a aprovação em todos os módulos referentes a uma habilitação técnica ou à aprovação em exames organizados pelos sistemas federal e estaduais de ensino conferem ao aluno o certificado de técnico de nível médio na referida habilitação.

Nessa direção, documento do MEC, que estabelece os parâmetros curriculares nacionais para a educação profissional (conteúdos mínimos, habilidades e competências básicas), considera que "a organização em módulos deverá proporcionar maior agilidade às instituições de formação profissional [...] uma vez que os cursos, programas e currículos poderão ser reestruturados e renovados periodicamente, segundo as emergentes e mutáveis demandas do mundo do trabalho" (Brasil, 1999, p. 18).

A digressão relativa às políticas federais, desenvolvidas como parte do programa educacional do PSDB coordenado por Paulo Renato Souza, Ministro da Educação nos dois mandatos de FHC (1995-2002), tem por objetivo indicar sua consonância com as políticas desenvolvidas no estado de São Paulo e, em particular, no CPS, no que diz respeito tanto às medidas destinadas a coibir a ampliação da rede quanto às concepções pedagógicas que orientaram políticas curriculares e processos de avaliação na instituição.

Levando em conta a legislação federal e o processo n. 119/97, do Conselho Estadual de Educação de São Paulo, no caso do CPS foram realizadas as mudanças previstas: manutenção do ensino médio de forma paralela, com matrículas em separado, nas escolas da rede estadual, com funcionamento no turno matutino, reservando os turnos vespertino e noturno para o ensino profissional, este último voltado preferencialmente para o alunado que já houvesse concluído o ensino médio e que trabalhasse durante o dia. A medida visava dar maior funcionalidade à rede, racionalizando seus recursos e, ao mesmo tempo, adequando-a à legislação federal e às normatizações estaduais. $\mathrm{O}$ ensino técnico passava a ter currículo próprio, organizado sob forma modular, com base no modelo das competências e com carga mínima prevista na legislação (Brasil, 1997).

O CPS elaborou no ano 2000 o documento Educação Profissional em São Paulo para afirmar seu projeto institucional de oferta de cursos, encaminhando-o

6 Os cursos passavam a ter periodicidade semestral e duração de 1.500 horas-aula, com 400 horas de estágio, totalizando 1.900 horas-aula (Moraes e Ferretti, 1999, p. 237). 
aos deputados estaduais da Assembleia Legislativa de São Paulo (ALESP) com os propósitos de apoiar a comunicação sobre a mudança da educação profissional e tecnológica no estado e apresentar "o novo modelo de educação profissional". A proposta "de adequação pedagógica e institucional do CPS ao tipo de gestão requerida pelo novo modelo" alinhava-se à perspectiva de "inserção ou reinserção do cidadão no mundo do trabalho e integração da economia paulista à situação cambiante do mercado em um mundo globalizado" (CPS, 2000).

A vitória do governo petista e as mudanças nas políticas de ensino médio e da educação profissional no país (decreto federal n. 5.154/2004) trouxeram novo dilema para a administração central do CPS: manter o ensino médio regular nas ETEC ou integrá-lo com o ensino técnico.

Documentos do CPS, do Sindicato dos Trabalhadores do CPS (SINTEEPS) e pesquisas de Sacilotto (2016) e de Santana (2016) apontam problemas para a efetiva implantação da forma integrada do ensino médio com a educação profissional técnica no CPS: redução da quantidade de vagas e alunos; aumento do custo/aluno, pelo fim do período parcial do ensino médio regular; necessidade de mudanças significativas nas organizações curriculares dos cursos para superar segmentação e desarticulação entre disciplinas, desconhecimento da concepção de integração pelos docentes e gestores e ausência de condições adequadas de aprendizagem dos alunos. Acrescentem-se a essas dificuldades as mudanças de concepção e de princípios ordenadores na construção dos currículos, definidos nas Diretrizes Curriculares para a Educação Profissional Técnica de Nível Médio (Resolução do Conselho Nacional de Educação/Câmara de Educação Básica - CNE/CEB 6/2012 e parecer CNE/CEB n. 11/2012).

Assim, embora o decreto federal n. 5.154/2004 retomasse a possibilidade de oferta do ensino técnico integrado ao ensino médio a partir do ano letivo de 2005, a primeira experiência de ensino integrado foi retomada apenas em 2010, com a habilitação profissional de Mecatrônica integrada ao ensino médio. Após 2005, as formas de oferta dos cursos permanecem idênticas àquelas disponíveis anteriormente, isto é, de ensino técnico nas formas concomitante e subsequente e de ensino médio, separadamente, com matrículas distintas ${ }^{8}$.

A reestruturação administrativa e pedagógica foi acompanhada pela ampliação da capacidade de atendimento das unidades de ensino existentes de modo a aumentar vagas disponíveis, incluída a oferta de ensino médio em ETEC que não o ofereciam. A criação de novas unidades começa no governo Alckmin/Lembo (2001-2007) e intensifica-se no governo Serra (2007-2010): de 138 ETEC e 33 FATEC, com 123 mil alunos e 11 mil trabalhadores, em 2007, a instituição passa a

7 Destinam-se a quem cursa o ensino médio e a quem já o tenha concluído, respectivamente.

8 O estado de São Paulo instituiu o ensino técnico integrado ao médio com o programa federal "Brasil Profissionalizado", de 2007, que liberou recursos aos estados visando fortalecer suas redes de educação profissional tecnológica como meta do Plano de Desenvolvimento da Educação (PDE). Em 2014, o CPS ofertava-o em 175 unidades (Lima, 2020, p. 102). 
ter 198 ETEC e 49 FATEC, com 196 mil alunos e 16 mil trabalhadores em 2010 (Quintino, 2020, p. 92).

Conforme relatório da Secretaria da Fazenda e Planejamento do Estado de São Paulo (SFP-SP), em 2002, os recursos do Programa Federal de Expansão da Educação Profissional (PROEP), viabilizados por meio do convênio entre Ministério da Educação (MEC) e Banco Interamericano de Desenvolvimento (BID), financiavam o desenvolvimento de projetos escolares nas então denominadas escolas técnicas (ETE) de São Paulo, Santos, Botucatu, Ribeirão Preto e São José do Rio Preto (Quintino, 2020, p. 91).

Os estudos de Sacilotto (2016) e Fiala (2017) mostram que, ao contrário de outras instituições estaduais de educação, como as três universidades públicas Universidade de São Paulo (USP), UNICAMP e UNESP —, autarquias de regime especial integradas à mesma secretaria estadual, o CPS nunca teve autonomia financeira, nem seu orçamento esteve vinculado legalmente a percentuais de receitas estaduais. A desvinculação orçamentária e a ausência de autonomia provocam alterações aleatórias no financiamento da rede de escolas, nas suas diferentes atividades de gestão, didático-pedagógicas e, nesse caso, na ampliação da oferta e na qualidade de ensino.

As escolas técnicas reagiram às oscilações e restrições orçamentárias (e por vezes à própria gestão do CPS, diretamente ou por indução) ao recorrerem a formas alternativas de financiamento, que Sacilotto (2016) caracteriza como "pactos fundacionais da política pública": projetos financiados por fundações e agências de fomento; recursos oriundos das cooperativas escolares (nas escolas "agrícolas"); parcela do montante do pagamento de inscrição dos candidatos ao exame de ingresso; contribuições dos alunos às Associações de Pais e Mestres das escolas, entre outras. Além disso, sua pesquisa enumera vários projetos, desenvolvidos nas ETEC e FATEC, financiados por fundações de direito privado, a exemplo da Fundação Vitae ${ }^{9}$ e da Fundação de Apoio à Tecnologia $(\text { FAT })^{10}$. O Programa de Apoio ao Ensino Técnico foi criado em 1996 pela Fundação Vitae - Apoio à Cultura, Educação e Promoção Social, com o objetivo de contribuir para o aperfeiçoamento da educação profissional técnica de nível médio no Brasil.

Em 2006, após a Vitae encerrar suas atividades, a FAT assume a gestão do programa em parceria com outras instituições, entre elas, Fundação Lemann (desde 2002), Instituto Unibanco, Banco Itaú BBA e Fundação Itaú Social a partir de 2007 (Fundação FAT, 2009, p. 13 apud Sacilotto, 2016). E passa a chamar-se "Parceiros-Vitae de Apoio ao Ensino Técnico e Agrotécnico", com os mesmos objetivos e formas de financiamento. No período entre 1996 e 2013 são financiados 96 projetos de ETEC do CPS, para atualização e construção de laboratórios em diferentes cursos (Fundação FAT, 2009, p. 13-14 apud Sacilotto, 2016).

9 Sobre a Fundação Vitae, consultar Almeida e Herência (2012).

10 FAT é uma fundação de direito privado, criada por professores da Fatec de São Paulo, em 1987, que organizou e realizou vestibulares e seleções de ingresso nas Fatec e Etec. Consultar: fundacaofat.org.br/fundacao/. Acesso em: 10 jul. 2020. 
O Relatório de Gestão 2004-2008 (CPS, 2009) relata que, no período, são celebrados 373 convênios, dos quais 97 para criação de classes descentralizadas ${ }^{11}$. As prefeituras municipais "destacam-se entre os parceiros que firmaram convênios com a instituição, tanto para as Classes Descentralizadas como para a implantação de novas ETECs e FATECs"e também parcerias com o setor privado: "a assinatura de vários convênios com usinas sucroalcooleiras, indústrias e empresas para cursos de formação e qualificação de seus funcionários, a maioria em Classes Descentralizadas", destacando o "papel fundamental da Fundação FAT para a concretização de convênios de grande relevância (CPS, 2009, p. 22-23; CPS, 2016, p. 6 apud Sacilotto, 2016).

\section{PRIVATIZAÇÃO NA EDUCAÇÃO PROFISSIONAL}

De acordo com informações da diretora do Grupo de Formulação de Análises Curriculares (GFAC) do CPS, Fernanda Demai (2019, p. 34), nos últimos 20 anos, a instituição, com a Unidade do Ensino Médio e Técnico (CETEC), realiza trabalho de elaboração e de reelaboração curricular por meio do "Laboratório de Currículo", "junto a especialistas e a instituições, públicas e privadas, priorizando a formação de parcerias".

Em 2000, com a publicação dos Referenciais Curriculares Nacionais da Educação Profissional de Nível Técnico pelo MEC, houve a explicitação do objetivo de romper com o paradigma do currículo da educação profissional técnica (EPT) focado em "conteúdos a serem ensinados" pelo novo "paradigma em implantação", com foco nas competências a serem desenvolvidas, nos saberes a serem construídos — "saber, saber ser e saber fazer". Nessa direção, de acordo com os referenciais, o currículo "deixa de ser um fim a ser alcançado, simples rol de conteúdos ensinados e aprendidos"(Demai, 2019, p. 24) para significar "um conjunto de situações-meio, pedagogicamente concebidas e organizadas para promover aprendizagens profissionais significativas" (Brasil, 2000, p. 11).

Por quase uma década, a organização da EPT de nível médio foi orientada pela tríade "competências-habilidades-bases tecnológicas" e construída com base em categorias denominadas "áreas profissionais", seguindo parâmetros dos organismos multilaterais, especialmente o Banco Mundial/BIRD, e "mudanças conceituais" introduzidas pelo Livro Branco da Comunidade Europeia em 1995. No governo Lula, há a emissão do novo decreto n. 5.154/2004, que substitui medida anterior e reintegra a educação profissional técnica ao ensino médio; mas apenas em 2008, com a resolução CNE/CEB n. 3, de 9 de julho de 2008, e o Catálogo Nacional dos Cursos Técnicos (CNCT) do MEC, o paradigma da EPT de nível médio foi remodelado, substituindo-se as "áreas profissionais" por "eixos tecnológicos", com

11 Formato autorizado pelo Conselho Estadual de Educação de São Paulo, em 1999, como meio de expansão da oferta do CPS utilizando-se de outros espaços institucionais, o que caracteriza movimento tendencial de precarização das condições de ensino, cf. Quintino (2020). 
vistas à superação do modelo das competências em prol da concepção de politecnia ou "núcleo politécnico comum para cada eixo tecnológico" (Machado, 2010, p. 93).

$\mathrm{Na}$ avaliação crítica do CPS, tanto os Referenciais Curriculares de 2000 como o CNTC de 2008 não traziam "informações suficientes para uma padronização curricular". Por isso, o CPS iria utilizar, para os cursos técnicos, "uma metodologia híbrida de estudos e formulações curriculares, buscando, além dos [...] referenciais legais, pesquisas junto ao setor produtivo, a outras instituições que ofertam EPT e outras instâncias governamentais, como o Ministério do Trabalho e Emprego" (Demai, 2019, p. 29). Com essas preocupações, haviam sido organizadas, em 2006, reuniões de trabalho e edições do Fórum de Educação Profissional, envolvendo as principais instituições que desenvolvem formação técnica e tecnológica no estado de São Paulo: CPS, Instituto Federal de Educação, Ciência e Tecnologia (IFSP), SENAI São Paulo, Associação Nacional de Educação Tecnológica, Serviço Nacional de Aprendizagem Comercial, Conselho Regional de Química 4a Região, Sindicato dos Técnicos Industriais de Nível Médio do Estado de São Paulo, Sindicato dos Tecnólogos do Estado de São Paulo.

A partir de 2008, são realizadas duas edições anuais "por iniciativa das instituições citadas", nas quais são trabalhados temas de relevância para a EPT e elaborados diagnósticos da sua situação no estado de São Paulo e no país, com ênfase no planejamento curricular - concepções e práticas de elaboração de desenhos curriculares a respectivos itinerários formativos e planos de curso. Os eventos contam, em média, com 200 participantes, entre professores e gestores educacionais, e são sediados pelas instituições que compõem o Fórum (Demai, 2019, p. 81-82).

Em 2012, é implementado o programa da Rede de Ensino Médio Técnico Vence, por meio do decreto n. 57.121/2011, com alterações introduzidas pelo decreto n. 58.185/2012 e resolução SE n. 78/2012. A oferta do ensino médio contava com componentes curriculares da base nacional comum, da parte diversificada e da formação profissional de nível médio, desenvolvidos pelas escolas públicas estaduais em regime de intercomplementaridade com unidades do CPS e do IFSP. Recentemente, com a disposição da reforma do ensino médio, lei federal $\mathrm{n}$. 13.145/2017, foram implantadas mudanças consideráveis nessa etapa do ensino, conforme indicado adiante.

Os elementos históricos da organização do ensino técnico de nível médio no CPS indicam que a elaboração e reelaboração dos currículos ocorreram conforme a legislação federal, com ajustes propiciados pelas injunções do Governo do Estado de São Paulo e pela autonomia relativa da instituição na organização pedagógica, além da administrativa e financeira (Moraes e Alencar, 2020).

\section{AGENTES PRIVADOS NAS POLÍTICAS CURRICULARES}

Os processos de conformação curricular na EPT deram-se por meio do desenvolvimento prioritário de parcerias com o "setor produtivo", contando, entre os anos de 2000 e 2018 , com 112 parceiros, que passaram de quatro em 2000 para 37 em 2017 e 70 em 2018. Desse total de instituições, houve 31 parcerias com autarquias estatais ou sem fins lucrativos e 81 parcerias com o setor privado, o que 
evidencia a crescente aproximação entre escola e mercado no período. Compreende-se por privado aquilo que é vinculado ao mercado e ao neoconservadorismo e que traz implicações para a democratização da educação (Peroni, 2015).

No Quadro 1, abaixo, são listadas instituições do setor público e, no Quadro 2 , são selecionados quatro parceiros do setor privado pela abrangência da sua interferência em cursos técnicos do CPS:

Quadro 1-Parcerias com setor público ou sem fins lucrativos no Centro Estadual de Educação Tecnológica Paula Souza (2000-2018).

\begin{tabular}{|c|c|}
\hline Câmara Municipal de São Paulo & $\begin{array}{l}\text { Instituto de Geociências da } \\
\text { Universidade de São Paulo }\end{array}$ \\
\hline Centro Cultural de Ourinhos & Ministério do Trabalho \\
\hline $\begin{array}{l}\text { Centro de Estudos e Pesquisas } \\
\text { de Administração Municipal }\end{array}$ & Movimento dos Trabalhadores Rurais Sem Terra \\
\hline $\begin{array}{l}\text { Centro de Referência de Álcool, } \\
\text { Tabaco e Outras Drogas }\end{array}$ & Prefeitura Municipal de Jundiaí \\
\hline $\begin{array}{c}\text { Comissão Municipal de Prevenção } \\
\text { de Doenças Aviárias }\end{array}$ & Prefeitura Municipal de Ourinhos \\
\hline Companhia de Engenharia de Tráfego & São Paulo Transporte \\
\hline $\begin{array}{l}\text { Companhia de Saneamento Básico do } \\
\text { Estado de São Paulo SA }\end{array}$ & Secretaria da Cultura \\
\hline Companhia do Metropolitano de São Paulo & Secretaria de Energia e Mineração \\
\hline Companhia Paulista de Trens Metropolitanos & $\begin{array}{l}\text { Secretaria de Habitação e Regularização } \\
\text { Fundiária/Prefeitura de Santo André }\end{array}$ \\
\hline Conselho Estadual de Entorpecentes & Secretaria do Estado de Saúde de São Paulo \\
\hline Conselho Regional de Administração/São Paulo & $\begin{array}{c}\text { Sindicato dos Técnicos de Nível Médio do Estado } \\
\text { de São Paulo }\end{array}$ \\
\hline $\begin{array}{c}\text { Conservatório Dramático e } \\
\text { Musical Dr. Carlos de Campos/Tatuí }\end{array}$ & Tribunal de Justiça de São Paulo \\
\hline $\begin{array}{l}\text { Cooperativa de Agricultores da } \\
\text { Região de Orlândia }\end{array}$ & $\begin{array}{l}\text { Universidade Estadual Paulista } \\
\text { "Júlio de Mesquita Filho" }\end{array}$ \\
\hline Departamento de Estradas e Rodagens & Universidade Estadual de Campinas \\
\hline Hospital Geral de Taipas & Universidade Federal de São Paulo \\
\hline $\begin{array}{l}\text { Instituto Butantan, Instituto de Botânica/Secretaria } \\
\text { do Meio Ambiente do Estado de São Paulo }\end{array}$ & \\
\hline
\end{tabular}

Fonte: Banco de dados da pesquisa.

Elaboração dos autores com base em Demai (2019, p. 93-101).

Conforme indicado no Quadro 2, os agentes privados envolvidos na definição da estrutura curricular dos cursos do CPS são grandes corporações de elevado patrimônio, que atuam na instituição desde 2005. Google e Microsoft intervêm nos mesmos cursos desde 2017, Rede Globo/Fundação Roberto Marinho, desde 2005, e foi a emissora que detectou "a necessidade de uma formação que mobilizasse 
competências técnicas para o trabalho na linguagem audiovisual e de multimeios dentro de sua própria realidade e demandou ao CPS a organização deste trabalho" (Guerra, 2019, p. 294) - parceria que resultou também na construção da ETEC Roberto Marinho. Por fim, a IBM Brasil intervém no CPS desde 2008, em dez cursos, oferecendo o programa P-Tech, direcionado para o eixo tecnológico informação e comunicação, nos Estados Unidos, Marrocos e Austrália. No CPS, alunos do programa realizam experiências de estágio com parceiros da empresa e obtêm o diploma de técnico de nível médio e superior de tecnologia correspondente.

Quadro 2 - Agentes privados e cursos técnicos sob sua intervenção no Centro Estadual de Educação Tecnológica Paula Souza (2000-2018).

\begin{tabular}{|c|c|c|}
\hline Instituição & Curso & Ano \\
\hline \multirow{4}{*}{ IBM Brasil } & Especialização em Java/WR & 2008,2013 \\
\hline & Especialização em desenvolvimento e produção mainframe & 2013 \\
\hline & $\begin{array}{l}\text { Técnico em desenvolvimento de sistemas integrado ao ensino } \\
\text { médio; técnico em informática integrado ao ensino médio; } \\
\text { técnico em informática para internet integrado ao ensino } \\
\text { médio; técnico em manutenção e suporte em informática } \\
\text { integrado ao ensino médio; técnico em redes de computadores; } \\
\text { técnico em telecomunicações }\end{array}$ & 2017 \\
\hline & $\begin{array}{l}\text { Ensino médio com qualificação profissional de administrador } \\
\text { de banco de dados }\end{array}$ & 2018 \\
\hline $\begin{array}{l}\text { Google } \\
\text { Microsoft }\end{array}$ & $\begin{array}{l}\text { Técnico em desenvolvimento de sistemas integrado ao ensino } \\
\text { médio; técnico em informática integrado ao ensino médio; } \\
\text { técnico em informática para internet integrado ao ensino } \\
\text { médio; técnico em manutenção e suporte em informática } \\
\text { integrado ao ensino médio; técnico em redes de computadores; } \\
\text { técnico em telecomunicações }\end{array}$ & 2017 \\
\hline \multirow[t]{2}{*}{$\begin{array}{l}\text { Rede Globo/ } \\
\text { Fundação Roberto } \\
\text { Marinho }\end{array}$} & $\begin{array}{c}\text { Técnico em administração empresarial — modalidade a } \\
\text { distância; técnico em gestão das pequenas empresas - } \\
\text { modalidade a distância; técnico em secretariado e assessoria - } \\
\text { modalidade a distância; }\end{array}$ & 2005 \\
\hline & Técnico em multimídia; técnico em produção de áudio e vídeo & 2011 \\
\hline
\end{tabular}

Fonte: Banco de dados da pesquisa.

Elaboração dos autores com base em Demai (2019, p. 93-101).

Por orientação do Laboratório de Currículo, os "parceiros do setor produtivo devem constar da ficha catalográfica que traz os créditos dos planos de curso, e [...] assinar parecer técnico de aprovação dos documentos de planejamento curricular (plano de curso)"(Araújo e Demai, 2019, p. 92), o que denota a incidência dessas parcerias com o setor produtivo na definição do que deve ser priorizado nos currículos.

De acordo com Araújo (2019, p. 251), coordenador-geral do ensino médio e técnico do CPS, em todos os currículos construídos nestes quase 20 anos,

A CETEC tem mediado esse processo, gerenciado os Laboratórios de Currículo (processo, produtos e equipes formadas por especialistas de empresas e 
das ETECs) relativos à (re)elaboração curricular, fazendo com que as definições sobre as atribuições, as competências profissionais, as instalações, as cargas horárias teóricas e práticas sejam acordadas pelo coletivo. [...] A descrição do perfil profissional é detalhada em atribuições e atividades, tendo como limite a análise do que está previsto para as funções/cargos das empresas consultadas e as da mesma família descritas na CBO - Classificação Brasileira de Ocupações do Ministério de Trabalho e Emprego.

O coordenador descreve com clareza a construção dos conteúdos curriculares orientados pela performance profissional demandados pelas empresas nos diferentes setores produtivos e famílias ocupacionais definidas na $\mathrm{CBO}$, segundo o modelo das competências. Explicita também, com objetividade, a apropriação institucional do significado da noção de competência, compreendida como saber operacional voltado à resolução prática de problemas em situações de trabalho, de acordo com as formulações de empresas e suas fundações e com as orientações dominantes no campo governamental.

As funções que estruturam as etapas do trabalho (planejamento, execução e controle) ajudam na definição dos componentes curriculares: disciplinas, projetos e atividades, ou seja, as funções que são referências para a organização do trabalho são, consequentemente, a base para a elaboração dos currículos de cursos técnicos e tecnológicos. Elas também, em alguns cursos, delimitam os módulos e as certificações. $\mathrm{Na}$ formação do técnico as experiências desenvolvidas dentro e fora da ETEC têm um papel importante na construção das competências previstas no currículo, isso porque trabalhamos com a definição de competência profissional. (Araújo, 2019, p. 251)

Embora o documento do Laboratório de Currículo não ignore a condição social e de desigualdade dos estudantes, confere-se distinção à formação por competências, vista como formação indutora de comportamentos adaptados (social e emocionalmente) às normas do mercado e, portanto, promotora da capacidade de trabalho, de empregabilidade, nos moldes das teorias econômicas marginalistas:

[...] as competências profissionais mobilizam valores e atitudes éticos e comportamentais, que levam a uma adaptabilidade do profissional técnico a situações profissionais e de vida diferenciadas, o que não deixa de ser uma condição de ingresso e permanência em funções, cargos, postos ou outras formas de trabalho, como o trabalho autônomo ou o trabalho a distância, entre outros. (Demai, 2019, p. 32)

A diretora do GFAC do CPS informa serem elaborados anualmente, em parceria público-privada, de três a cinco currículos novos, e reelaborados sistematicamente de 25 a 30 currículos por ano (Demai, 2019,p.36), o que denota permanentes modificações nos percursos de formação de estudantes alinhados às demandas apresentadas pelo mercado. $\mathrm{Na}$ fala da superintendente do CPS, Laura Laganá:

Um dos destaques que chamam a atenção para o trabalho do laboratório de currículos do CPS é a elaboração dos cursos em parceria com o setor produtivo, oferecendo formações estrategicamente direcionadas à demanda regional. $\mathrm{O}$ melhor 
caminho para formar profissionais bem preparados é ouvir o que as empresas têm a dizer sobre as suas necessidades - isso ajuda a manter o alto nível de empregabilidade dos alunos de ETECs e de FATECs. (Laganá, 2019, p. 11)

Com essa lógica, organiza-se, em 2011, a Agência Inova Paula Souza com o objetivo de garantir a simbiose necessária entre cursos e produção de conhecimento para a inovação tecnológica de empresas do setor privado. Segundo o balanço de gestão dos anos 2008-2012:

Para intensificar a proximidade do Paula Souza com o setor privado, no que diz respeito à contribuição para a inovação das empresas, a Inova participou de vários eventos e feiras tecnológicas buscando difundir estudos e oportunidades de transferência de conhecimentos e de tecnologias desenvolvidas pelos alunos da instituição. (CPS, 2012, p. 54-55)

Um elemento que explicita formalmente essa permanente aproximação é a inclusão do empreendedorismo, a partir de 2014, como competência transversal ou explícita na forma de componente curricular em todos os cursos e eixos tecnológicos do CPS. O alinhamento de foco comportamental, pragmático e de planejamento atualiza, uma vez mais, o léxico do mundo corporativo: resolução de problemas com ferramentas de gestão e criatividade, comunicação objetiva, iniciativa, visão estratégica e sistêmica orientadas às metas do setor produtivo, mensuração de impactos, sustentabilidade econômica (Demai, 2019).

No balanço de gestão do período seguinte, 2012-2016, a perspectiva do empreendedorismo na atuação do ensino técnico foi caracterizada como positiva do ponto de vista institucional:

Um recente foco na inovação e no empreendedorismo, presente em iniciativas da Agência Inova Paula Souza, assim como nos currículos de cursos, na metodologia de ensino e na capacitação de professores, direciona a formação em todos os níveis para as demandas mais atuais da economia. (CPS, 2016, p. 14)

A implementação do Vence em 2012 coloca o Programa em equivalência ao Ensino Técnico Integrado ao Médio (ETIM) no caso de o ensino médio ocorrer na escola da SEE-SP e o técnico na Etec do CPS, ou quando os ensinos médio e técnico ocorrem na escola da SEE-SP, sendo certificados pelo CPS (Maia, 2020).

Por fim, em 2018, com as disposições da lei federal n. 13.415/2017, que reformulou o ensino médio, o CPS implantou um novo modelo desse nível de ensino com a previsão de itinerários formativos constituídos de componentes curriculares da Base Nacional Comum Curricular (BNCC) combinados com uma parte diversificada. As "matrizes temáticas" estão sendo definidas pelo GFAC, em implantação desde 2018, antes mesmo da homologação da BNCC no estado (14 de dezembro de 2018) ${ }^{12}$.

12 A respeito, ver Piolli e Sala (2019). Na seção seguinte deste artigo serão evidenciadas as alterações que reduziram drasticamente os conteúdos nas matrizes curriculares dos cursos, oriundas dessas reformulações na política educacional. 
De acordo com o coordenador pedagógico do CPS, "as críticas à reforma do ensino médio não condizem com a realidade das novas propostas do CPS para o ensino básico". Para ele, "a flexibilização traz benefícios a um modelo nacional fragilizado":

Achar que o ensino médio unitário atende a todos pode ser arrogante ou idealista. No Acre, no sertão da Bahia e em São Paulo não se sustenta que todos tenham a mesma formação. A ideia é de que a formação esteja contextualizada com a região, os jovens e suas famílias. (Araújo, 2019)

Como já se indicou, o CPS aponta, com frequência, que o "setor produtivo" é formulador do currículo, conferindo-lhe sentido pragmático de atendimento às demandas de agentes privados por meio da adequação curricular às competências requisitadas pelo mercado. Cabe, então, perguntar: quando e como é garantido o espaço para a opinião dos sujeitos da escola?

No documento produzido pelo Laboratório de Currículo do Centro Paula Souza, o currículo escolar é "produto da manifestação humana, formatado com interesses objetivos de um ou mais grupos"(Demai, 2019, p. 43). Para o coordenador-geral dos ensinos médio e técnico,

Os currículos construídos nestes quase 20 anos são resultados de um consenso entre os que pretendem os demandantes e o que especialistas da CETEC, professores das Escola Técnicas Estaduais de São Paulo - ETECs - consideram pertinente à luz das experiências e das reflexões sobre a formação profissional de nível médio (Araújo, 2019, p. 251)

Apesar dessas intencionalidades do discurso, é importante pontuar que o documento institucional Observatório Escolar do CPS deixa explícita a concepção de modelo de administração escolar que sugere um mosaico de diferentes classificações do termo gestão: pedagógica, do espaço físico, participativa, de pessoas, de documentos, de parcerias, dos serviços de apoio (Ramos, 2011, p. 32). Todas essas dimensões são submetidas à avaliação por índice de desempenho, formulada pela direção e coordenação do CPS e executada pelo Conselho de Escola, via aplicação do instrumento de autoavaliação (Ramos, 2011, p. 63).

Essas diferentes classificações para as "práticas de gestão" buscam substituir o princípio de gestão democrática do ensino público, consagrado na Constituição Federa1/1988. No CPS, adota-se um modelo de gestão oriundo da administração empresarial, cuja abordagem obedece à sistemática planejar-executar-verificar-agir (ciclo Plan, Do, Check, Act - PDCA), de organizações tipicamente gerenciais.

O quadro de "parceiros" do setor privado, que submete o formato dos cursos à luz de suas demandas, e a perspectiva de gestão do CPS, prevista no Observatório Escolar, são fortes evidências de que o funcionamento institucional não prevê espaços democráticos nos quais a comunidade escolar possa participar com direito a voz e possibilidade de decisão sobre os rumos do processo educativo. Por outro lado, agentes privados possuem local privilegiado na formulação, na implementação e na avaliação da execução das suas demandas, concretizadas nas políticas curriculares do CPS. 
Partindo-se da concepção de currículo como uma seleção de conhecimentos considerados necessários em determinado tempo histórico, circunscrita do ponto de vista social, cultural e político, pode-se afirmar que a participação do setor privado é, portanto, decisiva na determinação do currículo das disciplinas do CPS.

\section{MATRIZES CURRICULARES DA HABILITAÇÃO PROFISSIONAL DE TÉCNICO EM ADMINISTRAÇÃO ${ }^{13}$}

No banco de dados disponibilizado pela $\mathrm{CETEC}^{14}$ para os primeiros semestres de 1998 e de 2008 (ano em que a oferta de técnico integrado ao médio teria voltado "com força", conforme relatório de gestão CPS 2008-2012, p. 26), bem como de 2020, verifica-se que a perspectiva do ensino integrado começa a alçar uma retomada, mas ainda está abaixo dos índices notados para 1998.

Com base no Gráfico 1, supõe-se que o formato integrado tenha sido praticamente extinto por volta do ano 2008, quando sua representatividade esteve próxima a $1 \%$ se comparada à dos outros formatos de ensino.

\section{Distribuição de Matrículas por tipo de ensino}

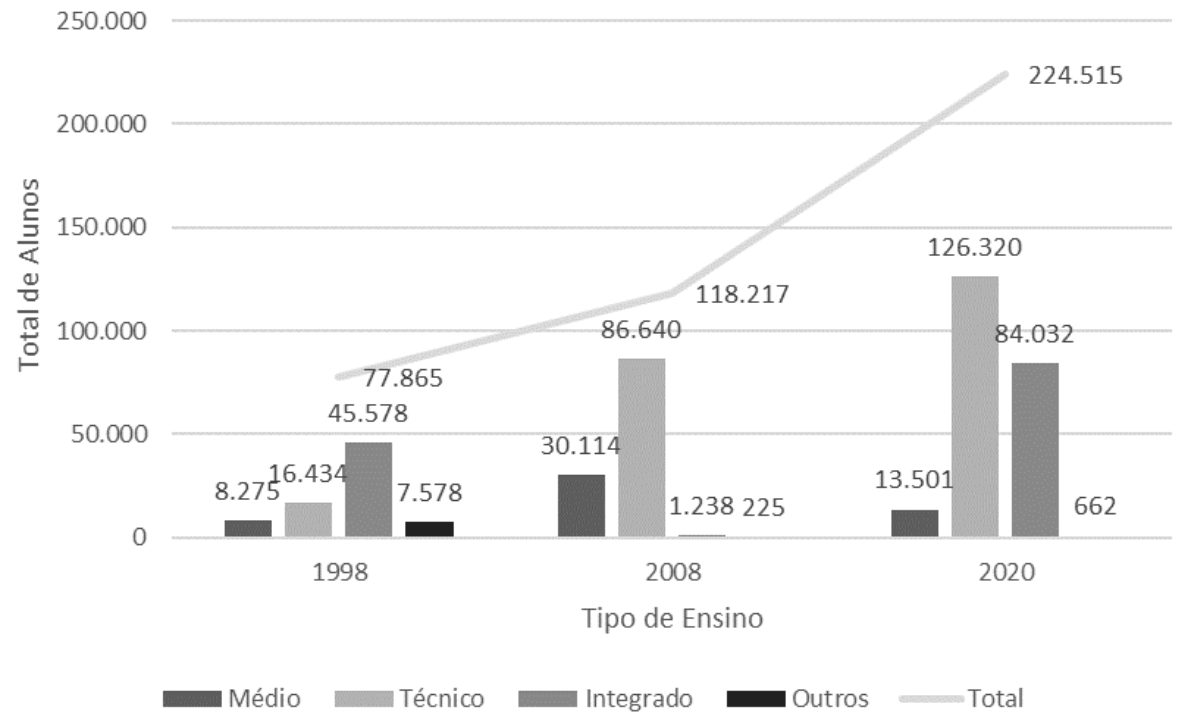

*Outros: inclui, no ano de 1998, os cursos de educação profissional de Formação Inicial e Continuada (FIC); em 2008, os cursos de EJA não integrada ao técnico, FIC e especialização; e, em 2020 os cursos de especialização. Fonte: Elaboração dos autores com base no banco de dados CETEC, 12 jul. 2020.

Gráfico 1 - Distribuição de matrículas por tipo de ensino.

13 A saber: Habilitação Profissional de Técnico em Administração; Técnico em Administração Integrado ao Ensino Médio (ETIM); e Ensino Médio com habilitação profissional de Técnico em Administração (NOVOTEC). Todas as matrizes curriculares aqui apresentadas foram extraídas de seus respectivos planos de curso.

14 Mapeamento de totais de alunos. Disponível em: cpscetec.com.br/. Acesso em: 12 jul. 2020. 
Observa-se no gráfico ampliação no número de vagas gerais para o período, que passaram de 77.685 em 1998 para 118.217 em 2008. Em 2020, estão matriculados 224.515 alunos nos ensinos técnico, médio integrado e médio. Esse aumento foi acompanhado da retomada dos cursos integrados de nível médio, que passaram a incluir, desde 2018 e em boa parte das escolas técnicas, "o Ensino Médio com o V Itinerário Formativo (Técnico e Profissional) - MTec, [...]. Em 2020, esta proposta curricular foi incorporada ao Programa NOVOTEC da Secretaria de Desenvolvimento Econômico" (Maia, 2020, p. 316).

O eixo Gestão e Negócios, conforme dados da CETEC, agrupa o maior número de matrículas no primeiro semestre de $2020\left(89.249\right.$ alunos, ou 39,8\% $\left.0^{15}\right)$ seguido pelos eixos Informação e Comunicação (31.696 alunos, ou 14,1\%) e Controle e Processos Industriais (27.771 alunos, ou 12,4\%).

Entre os cursos ofertados pelo CPS, analisa-se o de Administração por ser ele um dos que compõem o eixo Gestão e Negócios e reunir o maior número de estudantes dos cursos técnicos no ano de 2020. Segundo os últimos dados consolidados divulgados no banco de dados da CETEC, do total de 224.515 matriculados, incluindo somente o ensino médio, o curso de Administração detinha $50.391^{16}$ matrículas $(22,4 \%)$, considerando-se cursos técnicos presenciais e a distância, concomitantes, subsequentes e integrados.

No currículo do curso de Administração em Educação Profissional Técnica de Nível Médio, entre os anos 2000 e 2018, constam as seguintes parcerias, conforme Quadro 3.

Quadro 3 - Parceiros na formulação dos cursos de administração (2005-2018).

\begin{tabular}{|c|c|c|}
\hline Ano & Parceiros & Cursos \\
\hline 2005 & $\begin{array}{c}\text { Rede Globo de Televisão/Fundação Roberto } \\
\text { Marinho. }\end{array}$ & $\begin{array}{c}\text { Técnico em administração empresarial - } \\
\text { modalidade a distância. }\end{array}$ \\
\hline 2016 & $\begin{array}{c}\text { Representação da Organização das Nações } \\
\text { Unidas para a Educação, a Ciência e a } \\
\text { Cultura no Brasil. }\end{array}$ & $\begin{array}{l}\text { Técnico em administração integrado ao } \\
\text { ensino médio. }\end{array}$ \\
\hline \multirow[t]{2}{*}{2017} & $\begin{array}{c}\text { Representação da Organização das Nações } \\
\text { Unidas para a Educação, a Ciência e a } \\
\text { Cultura no Brasil. }\end{array}$ & $\begin{array}{l}\text { Técnico em administração integrado ao } \\
\text { ensino médio. }\end{array}$ \\
\hline & $\begin{array}{l}\text { Conselho Regional de Administração/São } \\
\text { Paulo; Universidade Metodista de São Paulo. }\end{array}$ & Técnico em administração. \\
\hline 2018 & $\begin{array}{l}\text { Conselho Regional de Administração/São } \\
\text { Paulo; Dura Automotive. }\end{array}$ & $\begin{array}{c}\text { Ensino médio com habilitação profissional } \\
\text { de técnico em administração. }\end{array}$ \\
\hline
\end{tabular}

Fonte: Banco de dados da pesquisa.

Elaboração dos autores com base em Araújo e Demai (2019, p. 93-101).

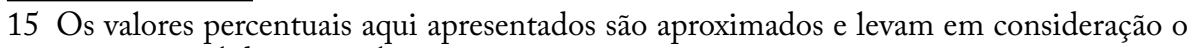
número total de matrículas por ano.

16 Excluiu-se o Ensino Médio com Qualificação Profissional de Auxiliar Administrativo, de Auxiliar de Finanças e de Auxiliar de Marketing e Comercial - MQTec (NOVOTEC) por não ser um curso com habilitação técnica, como os demais. 
A respeito dessas parcerias, entende-se que a atuação da Representação da Organização das Nações Unidas para a Educação, a Ciência e a Cultura (UNESCO) no Brasil e da Universidade Metodista de São Paulo estejam alinhadas com as propostas fins dessas instituições, assim como é previsível a participação do Conselho Regional de Administração na medida em que ele é responsável por orientar, disciplinar e fiscalizar a profissão de administrador. Semelhante à Rede Globo de Televisão/Fundação Roberto Marinho, anteriormente mencionada, a Dura Automotive, com matriz nos Estados Unidos e filial em Rio Grande da Serra (SP) ${ }^{17}$, atua com a criação da Etec Rio Grande da Serra. A parceria com o CPS, iniciada em 2018, incluiu a colaboração do Conselho Regional de Administração para a oferta do curso Ensino Médio com Habilitação Profissional de Técnico em Administração (MTec) e do curso Técnico em Logística, dessa vez em atuação conjunta com as empresas Alcis Ltda. (que oferece softwares para logística) e Verlog Logística \& Transportes Ltda. (cf. Araújo e Demai, 2019).

No processo seletivo (vestibulinho) da ETEC, o aluno pode escolher entre o ETIM $^{18}$, o Ensino Médio com Habilitação Profissional de Técnico em Administração - MTec (NOVOTEC) ${ }^{19}$ e o Projeto de Articulação da Formação Profissional Média e Superior $\left(\mathrm{AMS}^{20}\right)$.

Abaixo apresentamos um quadro síntese comparativo entre ETIM e NOVOTEC, para indicar mudanças introduzidas com a adequação dos cursos do CPS à $\mathrm{BNCC}$ e à reforma do ensino médio, bem como os prejuízos dessa política educacional ao conteúdo da escola:

Em relação à parte que cabe à formação técnica e profissional, nosso comparativo inclui o curso com Habilitação Profissional de Técnico em Administração ${ }^{21}$.

Tanto o curso de Habilitação Profissional de Técnico em Administração quanto o ETIM e o NOVOTEC, relacionadas no Quadro 4, permitem formações intermediárias. Embora as certificações intermediárias e o diploma ao fim do curso sejam equivalentes, as formações possuem disciplinas com diferentes nomenclaturas e carga horária.

As bibliografias apresentadas nos planos de ensino dos cursos ETIM e NOVOTEC possuem as mesmas referências para conteúdos da formação geral e para a habilitação em Administração. Isso sugere que, apesar das disciplinas terem nomenclaturas ou conteúdos distribuídos diferentemente, os cursos possuem um referencial de trabalho comum.

17 Informações disponíveis em: duraauto.com.br. Acesso em: 26 jul. 2020.

18 Matriz referenciada no Plano de Curso 213, disponibilizado pela Etec Raposo Tavares. Disponível em: etecraposotavares.com.br/cursos/etim-administracao/. Acesso em: 13 jul. 2020.

19 Matriz referenciada no Plano de Curso 427, disponibilizado pela Etec Prof. Adolpho Arruda Mello. Disponível em: etecarrudamello.com/cursos-tecnicos. Acesso em: 16 jul. 2020.

20 Permite que em cinco anos o aluno complete o ensino médio, técnico e superior tecnológico.

21 Matriz referenciada no Plano de Curso 421, Etec Parque da Juventude. Disponível em: etecparquedajuventude.com.br/Cursos/curso.php? curso=5\&u=0\&t=2. Acesso em: 15 jul. 2020 . 


\section{Quadro 4 - Comparação entre matrizes curriculares ETIM e NOVOTEC - Conteúdos da Base Nacional Comum Curricular.}

\begin{tabular}{|c|c|c|}
\hline Características & ETIM & NOVOTEC \\
\hline Total de horas & 3.080 horas-aula. & $\begin{array}{l}2.160 \text { horas-aula; carga } \\
\text { horária técnica é maior. }\end{array}$ \\
\hline $\begin{array}{l}\text { Matemática, língua portuguesa, literatura e } \\
\text { comunicação profissional. }\end{array}$ & 480 horas-aula. & 360 horas-aula. \\
\hline $\begin{array}{l}\text { Língua estrangeira moderna - inglês e } \\
\text { comunicação profissional. }\end{array}$ & \multicolumn{2}{|c|}{$\begin{array}{l}\text { Manutenção da carga horária: } 80 \text { horas-aula por } \\
\text { ano, totaliza } 240 \text { horas-aula. }\end{array}$} \\
\hline Espanhol (componente não obrigatório). & \multicolumn{2}{|c|}{ Manutenção da carga horária de 80 horas-aula. } \\
\hline $\begin{array}{l}\text { Filosofia e sociologia, } \\
\text { ambas com diminuição da carga horária a 1/3. }\end{array}$ & 120 horas-aula. & $\begin{array}{l}40 \text { horas-aula; } \\
\text { filosofia na } 2^{\text {a }} \text { série, } \\
\text { sociologia na } 3^{\text {a }} \text { série. }\end{array}$ \\
\hline $\begin{array}{l}\text { Arte, com redução de carga horária, mantida no } \\
1^{\circ} \text { ano do ensino médio. }\end{array}$ & 120 horas-aula. & 80 horas-aula. \\
\hline $\begin{array}{l}\text { Educação física, história, geografia, física, } \\
\text { química e biologia reduzidas a um semestre, } \\
\text { passando a ocorrer somente no } 1^{\circ} \text { e } 2^{\circ} \text { anos do } \\
\text { ensino médio. }\end{array}$ & $\begin{array}{l}80 \text { horas-aula por ano, } \\
\text { totaliza } 240 \\
\text { horas-aula. }\end{array}$ & $\begin{array}{l}80 \text { horas-aula apenas no } \\
1^{\circ} \text { e } 2^{\circ} \text { ano, totaliza } 160 \\
\text { horas-aula. }\end{array}$ \\
\hline \multicolumn{3}{|c|}{$\begin{array}{l}\text { Formações intermediárias de técnico em administração por módulos: } \\
\text { Módulo I ou } 1^{\circ} \text { ano: qualificação profissional técnica de nível médio de auxiliar administrativo. } \\
\text { Módulos I + II ou } 1^{\circ}+2^{\circ} \text { anos: qualificação profissional técnica de nível médio de assistente administrativo. } \\
\text { Módulos I + II + III ou } 1^{\circ}+2^{\circ}+3^{\circ} \text { anos: habilitação profissional de técnico em administração. }\end{array}$} \\
\hline
\end{tabular}

ETIM: Ensino Técnico Integrado ao Ensino Médio; NOVOTEC: Ensino Médio com Habilitação Profissional de Técnico em Administração.

Fonte: Banco de dados da pesquisa.

Elaboração dos autores com base nas matrizes curriculares selecionadas.

Entretanto, ao comparamos os cursos concomitantes e subsequentes no que concerne à parte profissional técnica, nota-se que há 15 referências comuns e 20 divergentes. Destas, nove constam só nos integrados e 11 no de Técnico em Administração, e apenas 12 autores aparecem citados somente em um ou em outro plano, o que fornece indícios de que haja um núcleo comum estruturante nos cursos em Administração, possibilitando certificações e diplomas com a mesma denominação.

A interdisciplinaridade aparece citada em todos os planos de curso, mas alcança evidência no curso NOVOTEC, posto que a ele se reserva uma disciplina, com carga horária 100\% prática, denominada "Projeto integrador I e II" e ofertada na $1^{\mathrm{a}}$ e $2^{\mathrm{a}}$ séries, com total de 160 horas-aula. Isso sugere haver diálogo entre os professores do Projeto Integrador e da Base Comum e Técnica e entre os professores do Projeto Integrador e Comunidade Escolar.

Nas cargas horárias de conteúdo técnico e profissional, o MTec (NOVOTEC) em Administração apresenta o total de 1.440 horas-aula; destas, quase metade, ou 760 horas-aula, acontecem na $3^{\mathrm{a}}$ série do ensino médio. Isso está em relação inversa ao que se observa para os conteúdos da BNCC, reduzidos a 440 horas-aula, o que equivale a quatro/cinco disciplinas, a saber: "Língua Portuguesa, Literatura e Comunicação Profissional", "Língua Estrangeira Moderna Inglês e Comunicação 
Profissional", "Matemática" "Língua Estrangeira Moderna — Espanhol” (quando ocorre) e "Sociologia", sendo estas duas últimas restritas à $3^{a}$ série.

Em relação ao Etim em Administração, reservam-se ao conteúdo técnico e profissional 1.320 horas-aula, distribuídas de modo mais uniforme que no NOVOTEC ao longo das séries do ensino médio, a saber: 400 horas-aula na $1^{\mathrm{a}}$ série; 480 horas-aula na $2^{a}$ SSérie e 440 horas-aula na $3^{a}$ série.

Já o curso Técnico em Administração possui o total de 1.500 horas-aula, igualmente distribuídas em 500 horas-aula por módulo de curso, o que permite afirmar que esse curso possui carga horária técnica e profissional maior que a dos integrados investigados. Todavia, se levarmos em consideração que ele inclui, conforme consta no plano de ensino, as disciplinas "Linguagem, Trabalho e Tecnologia" (com 40 horas-aula e foco em competências de Língua Portuguesa e Comunicação Profissional em Língua Materna) e "Inglês Instrumental" (também com 40 horas-aula), entendendo que essas duas disciplinas, nos cursos integrados, teriam alguns aspectos correspondentes aos conteúdos trabalhados na BNCC e, portanto, poderiam ser subtraídas da contagem, teríamos 1.420 horas-aula de conteúdo estritamente voltado à área técnica e profissional. Acrescenta-se que, para os três currículos, existe ainda uma carga horária de 120 horas reservada ao Trabalho de Conclusão de Curso.

Quando nos voltamos somente aos cursos ETIM e NOVOTEC, cabe destacar que o primeiro possui carga horária total de 4.400 horas-aula, enquanto o segundo soma 3.600 horas-aula, o que representa uma diferença de 800 horas-aula de estudos a mais para o ensino integrado e equivale a mais da metade da carga horária reservada à parte técnica e profissional do NOVOTEC, ou cerca de $37 \%$ de sua carga horária reservada aos conteúdos da BNCC.

Apesar de o NOVOTEC possuir um pouco mais de carga horária reservada à formação técnica e profissional, há uma perda bastante significativa em termos de apropriação dos conhecimentos historicamente constituídos pela humanidade, com ausência de teóricos e clássicos na bibliografia.

Com base na observação das matrizes curriculares aqui discutidas, assumindo-se o fazer currículo como ato político, pode-se afirmar que a reforma do ensino médio e a BNCC aprofundam o processo de aceleração do tempo de formação profissional de nível médio, o seu aligeiramento, e, embora a certificação por competência possa tornar os jovens aptos a se inserirem no mundo do trabalho, ela o faz de forma restrita, usurpando-os do seu direito pleno à educação.

Com a diminuição de carga horária nos cursos do NOVOTEC, não é difícil deduzir que há esvaziamento das práticas educativas e dos conteúdos de ensino. Um olhar mais atento às matrizes curriculares pode revelar um processo drástico de redução de conhecimentos ofertados aos estudantes, uma vez que se prioriza o ensino de conteúdos instrumentais, aparentemente mais úteis às competências profissionais, reservando-lhes maior carga horária, em detrimento do ensino de disciplinas de formação geral, distanciando os alunos de uma formação integral e humanística. Embora as mudanças curriculares provoquem perdas em ambos os formatos de ensino médio, verifica-se que a flexibilização introduzida no NOVO- 
TEC cria nova segmentação interna (dualidade?) na oferta do ensino médio — um formato estritamente voltado ao mercado e outro, mais abrangente, preparatório para os cursos superiores.

\section{CONSIDERAÇÕES FINAIS}

Contata-se, na análise realizada, um processo de dupla privatização na e por meio da política de educação profissional paulista: por uma via endógena, envolvendo importação de ideias, técnicas e práticas do setor privado para a formatação do setor público, de modo semelhante ao que ocorre nas empresas, e, paralelamente, um crescente e ativo papel de agentes privados de distintas naturezas na formulação de políticas (cf. Ball e Youdell, 2007; Ball, 2012).

Isso confere uma característica peculiar ao CPS: a escola permanece como propriedade estatal, mas passa a ter lógica e conteúdo orientados pelo mercado. $\mathrm{O}$ estudo permite afirmar que os currículos no CPS são conformados em simbiose com demandas advindas do mercado e, também, em acordo com as legislações em vigência.

No contexto da Reforma do Estado e da Nova Gestão Pública, são redefinidas as superestruturas para o aprofundamento do avanço do setor mercantil no público, sob a representação da maior participação da sociedade civil e a utilização de diagnóstico permanente de insuficiência da cobertura do poder estatal para melhorar a qualidade dos serviços públicos.

Nessa homogeneização da sociedade civil repousa a real intencionalidade do privilégio de espaços para empresas e empresários, em oposição à participação ativa das comunidades subalternas. Vale alertar, portanto, que no seio da sociedade civil há desenhos societários antagônicos, uma bad civil society, que desenvolve projetos mercadológicos nutrindo interesses próprios de lucros acima das vidas, investindo também em correntes autoritárias e totalitárias (Chambers e Kopstein, 2001).

Com essa estratégia, foram favorecidas as dimensões políticas e ideológicas dirigidas ao empobrecimento dos conteúdos de ensino e dos pressupostos político-pedagógicos da formação de nível técnico, por meio da apropriação de um léxico ilusório de parcerias, empreendedorismo, competências, utilizado para disputar a formação na escola pública, com invólucro empresarial.

Paralelamente, o formato mais atual adotado para o ensino médio, o NOVOTEC, que integra BNCC e ensino técnico, propõe profissionalização de tempo reduzido para jovens, voltada ao estrito atendimento às demandas de competências do mercado. Comparado ao formato implantado anteriormente, o ETIM, apresenta um enxugamento da carga horária de conteúdos relacionados à BNCC.

$\mathrm{O}$ crescente empobrecimento dos currículos escolares, com a retirada e o esvaziamento dos fundamentos teóricos científicos, humanísticos e tecnológicos, imprescindíveis para a compreensão crítica da realidade social e a participação ativa na moderna sociedade tecnológica, expressa o pragmatismo político e econômico das reformas educacionais impostas pelas agendas neoliberais dos governos federal e estadual. 
Nessa direção, pode-se supor que o projeto de desmonte do ensino médio e técnico das escolas estaduais e federais, tal como foi possível constatar no CPS, está em consonância com a ausência de demandas socioeconômicas por produção de ciência e tecnologia em um país cuja economia se especializa em criar empregos e/ou ocupações precarizadas, de baixa qualificação (com a destruição permanente de cadeias produtivas, o declínio da participação da indústria de transformação, especialmente a metalmecânica, no produto interno bruto - PIB).

Em outras palavras: o projeto de privatização do ensino técnico público, associado à mercadorização da educação, nestes tempos de globalização financeira, estaria voltado - além da disputa pelos fundos públicos — à conformação de uma nova subjetividade ao estudante trabalhador, adaptado à ausência do emprego e privado de seus direitos sociais, destinado ao empreendedorismo, isto é, ao trabalho precário, subcontratado e sub-remunerado?

\section{REFERÊNCIAS}

ALMEIDA, G. S. B. A.; HERENCIA, J. L. A Fundação Vitae e seu legado para a cultura brasileira - Parte I: fontes conceituais, linhas diretivas, programas próprios e legado. In: SEMINÁRIO INTERNACIONAL DE POLÍTICAS CULTURAIS, 3., 2012, Rio de Janeiro. Anais [...]. Rio de Janeiro: Fundação Casa de Rui Barbosa, 2012. ARAUJO, A. Em 2019, Ensino Médio no Centro Paula Souza terá mais modalidades. Do Portal do Governo, 03 jan. 2019. Disponível em: saopaulo.sp.gov.br/spnoticias/ em-2019-ensino-medio-no-centro-paula-souza-tera-mais-modalidades/. Acesso em: 25 ago. 2020.

BALL, S.J. La micropolítica de la escuela: hacia uma teoria de la organización escolar. Buenos Aires: Paidós, 1989.

BALL, S. J. Global Education Inc. New Policy Networks and the Neoliberal Social Imaginary. Didcot: Routledge, 2012.

BALL, S. J.; YOUDELL, D. Hidden privatisation in public education. Brussels: Education International, 2007.

BALL, S.J.; MAGUIRE, M.; BRAUN, A. Como as escolas fazem as políticas: atuação em escolas secundárias. Ponta Grossa: Editora UEPG, 2016.

BRASIL. Lei Federal n. 5.692/1971, de 11 de agosto de 1971. Fixa Diretrizes e Bases para o ensino de $1^{\circ}$ e $2^{\circ}$ graus, e dá outras providências. Presidência da República, Casa Civil, Subchefia para Assuntos Jurídicos. Brasília, DF: 1971. Disponível em: http:// www.planalto.gov.br/ccivil_03/leis/15692.htm. Acesso em: 8 dez. 2021.

BRASIL. Constituição da República Federativa do Brasil. Brasília, DF: Senado Federal/Centro Gráfico, 1988.

BRASIL. Lei n. 9.394/1996, de 20 de dezembro de 1996. Estabelece as diretrizes e bases da educação nacional. Brasília, DF, 1996. Disponível em: http://www.planalto. gov.br/ccivil_03/leis/19394.htm. Acesso em: 08 dez. 2021. 
BRASIL. Decreto Federal n. 2.208/1997 de 17 de abril de 1997. Brasília, DF, 1997. Disponível em: http://portal.mec.gov.br/seesp/arquivos/pdf/dec2208.pdf. Acesso em: 08 dez. 2021.

BRASIL. Diretrizes curriculares nacionais para a educação profissional de nível técnico. Brasília: Conselho Nacional de Educação, 1999.

BRASIL. Educação Profissional: referenciais curriculares nacionais da educação. Brasília: Ministério da Educação, 2000. Disponível em: http://portal.mec.gov.br/setec/ arquivos/pdf/introduc.pdf. Acesso em: 08 dez. 2021.

BRASIL. Decreto Federal n. 5.154/2004 de 23 de julho de 2004. Presidência da República, Casa Civil, Subchefia para Assuntos Jurídicos. Brasília, DF, 2004. Disponível em: http://www.planalto.gov.br/ccivil_03/_ato2004-2006/2004/decreto/d5154.htm. Acesso em: 08 dez. 2021.

BRASIL. Parecer CEB n. 11/2012. Diretrizes Curriculares Nacionais para a Educação Profissional Técnica de Nível Médio. Brasília: Ministério da Educação, 2012a.

BRASIL. Resolução CNE/CEB n. 6/2012, de 20 de setembro de 2012. Define Diretrizes Curriculares Nacionais para a Educação Profissional Técnica de Nível Médio. Ministério da Educação. Conselho Nacional de Educação. Câmara de Educação Básica. Brasília, DF, 2012b. Disponível em: http://portal.mec.gov.br/index.php?option=com docman\&view=download\&alias=11663-rceb006-12-pdf\&category_slug=setembro2012-pdf\&Itemid=30192. Acesso em: 8 dez. 2021.

CPS — Centro Estadual de Educação Tecnológica Paula Souza. Educação Profissional em São Paulo. São Paulo: CPS, 2000.

CPS - Centro Estadual de Educação Tecnológica Paula Souza. Relatório de Gestão 2004-2008. São Paulo: CPS, 2009.

CPS - Centro Estadual de Educação Tecnológica Paula Souza. Sobre o Centro Paula Souza. Disponível em: https://www.cps.sp.gov.br/sobre-o-centro-paula-souza/. Acesso em: 01 jul. 2019.

CHAMBERS, S.; KOPSTEIN, J. Bad civil society. Political Theory, v. 29, n. 6, p. 837-865, dez. 2001. Disponível em: https://www.jstor.org/stable/3072607. Acesso em: 8 dez. 2021.

COHN, A. O modelo de proteção social no Brasil: qual o espaço da juventude? In: NOVAES, R; VANNUCHI, P. (orgs.). Juventude e sociedade: trabalho, educação, cultura e participação. São Paulo: Perseu Abramo, 2004. p. 160-179.

DEMAI, F. Missão, concepções e práticas do grupo de formulação e análises curriculares (GFAC). In: ARAÚJO, A.; DEMAI, F. (orgs.). Currículo escolar em laboratório: a Educação Profissional e Tecnológica. São Paulo: CPS, 2019. p. 21-130.

FIALA, D. A. S. A política de expansão da Educação Profissional Tecnológica de Graduação Pública no Estado de São Paulo (2000-2007). 2007. Dissertação (Mestrado em Educação) - Universidade Estadual de Campinas, Campinas, 2017.

GUERRA, L. A.F. Construção de currículo no eixo tecnológico de Produção Cultural e Design. In: ARAÚJO, A. M.; DEMAI, F. (orgs.). Currículo escolar em laboratório: a Educação Profissional e Tecnológica. São Paulo: CPS, 2019. p. 288-300. 
KORITIAKE, L. A. Reestruturação produtiva e educação: um estudo sobre a proposta do Centro Estadual de Educação Tecnológica Paula Souza para o ensino médio e técnico. 2008. Tese (Doutorado em Educação) - Universidade Metodista de Piracicaba, Piracicaba, 2008.

LAGANÁ, L. Prefácio. In: ARAÚJO, A. M.; DEMAI, F. (orgs.). Currículo escolar em laboratório: a Educação Profissional e Tecnológica. São Paulo: CPS, 2019.p. 11-12. LAVAL, C. A Escola não é uma empresa: o neoliberalismo em ataque ao ensino público. Londrina: Plana, 2004.

LIMA, S. H. Educação Profissional e Tecnologia Pública no Estado de São Paulo: um estudo a partir da expansão do Centro Paula Souza. 2020. Dissertação (Mestrado Profissional) - Faculdade Tecnológica, São Paulo, 2020.

MACHADO, L. Organização da Educação Profissional e Tecnológica por eixos tecnológicos. Linhas Críticas, Brasília, v. 16, n. 30, p. 80-108, jan./jun. 2010. https:// doi.org/10.26512/lc.v16i30.3571

MAIA, L. C. Z. Mapeamento das escolas técnicas do Centro Paula Souza. Ano 24. Vol. 46. São Paulo: CPS, 2020. Disponível em: http://www.memorias.cpscetec. com.br/bdcetec/mapeamento/documentos/Unidades2020_1Sem.pdf. Acesso em: 08 dez. 2021.

MORAES, C. S. V. O que há de novo na educação profissional no Brasil. Trabalho \& Educação, Belo Horizonte, v. 8, p. 13-45, jan./jun. 2001. Disponível em: https://periodicos.ufmg.br/index.php/trabedu/article/view/9183. Acesso em: 08 dez. 2021.

MORAES, C. S. V. Educação permanente: direito de cidadania, responsabilidade do Estado. Trabalho, Educação e Saúde, v. 4, n. 2, p. 395-416, set. 2006. https://doi. org/10.1590/S1981-77462006000200011

MORAES, C. S. V. O ensino médio e as comparações internacionais: Brasil, Inglaterra e Finlândia. Educação \& Sociedade, Campinas, v.38, n. 139, p. 405-429, abr./jun. 2017. https://doi.org/10.1590/ES0101-73302017177657

MORAES, C. S. V.; ALENCAR, F. Políticas de educação profissional no estado de São Paulo (Relatório de Pesquisa). São Paulo: FAPESP, 2020.

MORAES, C. S. V.; FERRETTI, C. J. (coords.). Diagnóstico da formação Profissional: ramo metalúrgico. São Paulo: CNM/Unitrabalho, 1999.

OLIVEIRA, J. B. Novos rumos da formação profissional. SEMINÁRIO INTERNACIONAL FIEMG. Anais [...], Belo Horizonte, 1995. Belo Horizonte: FIEMG, 1995.

PERONI, V. M. V. Implicações da relação público-privado para a democratização da educação no Brasil. In: PERONI, V. M. V. (org.). Diálogos sobre as redefinições no papel do Estado e nas fronteiras entre o público e o privado na educação. São Leopoldo: Oikos, 2015. p. 15-34.

PIOLLI, E.; SALA, M. O Novotec e a implementação da Reforma do Ensino Médio na rede estadual paulista. Crítica Educativa, v. 5, n. 1, 2019. https://doi.org/10.22476/ revcted.v5i1.424 
QUINTINO, R. M. Classes descentralizadas do Centro Paula Souza na região metropolitana do Vale do Paraíba e litoral norte do estado de São Paulo. 2020. Dissertação (Mestrado Profissional em Gestão e Desenvolvimento da Educação Profissional) - Faculdade Tecnológica, São Paulo, 2020.

SACILOTTO, J. V. A educação profissional na agenda de políticas públicas de educação no Estado de São Paulo e a expansão do Centro Estadual de Educação Tecnológica Paula Souza. 2016. Tese (Doutorado em Educação) - Universidade Estadual de Campinas, Campinas, 2016.

SANTANA, A. C. R. Representações sociais de professores de escolas técnicas estaduais paulistanas sobre a formação técnica integrada ao ensino médio. 2016. Dissertação (Mestrado em Educação) - Universidade Cidade de São Paulo, São Paulo, 2016.

SÃO PAULO (Estado).Lei n. 952/1976, de 30 de janeiro de 1976. Cria a a Universidade Estadual Paulista "Júlio de Mesquita Filho" e dá providências correlatas. Diário Oficial do Estado de São Paulo, São Paulo, 31 jan. 1976.

SÃO PAULO (Estado). Conselho Estadual de Educação de São Paulo. Processo n. 119/97, de 30 de julho de 1997. Diretrizes para elaboração de Regimento das Escolas no Estado de São Paulo. Diário Oficial do Estado de São Paulo, São Paulo, 1 ago. 1997. SÃO PAULO (Estado). Lei complementar n. 1.044, de 13 de maio de 2008. Institui o Plano de Carreiras, de Empregos Públicos e Sistema Retribuitório dos Servidores do Centro de Educação Tecnológica "Paula Souza". Diário Oficial do Estado de São Paulo, São Paulo, 2008.

SÃO PAULO (Estado). Resolução SE n. 18/2019. São Paulo: SEDUC, 2019.

SOUZA, A. N. Professores, modernização e precarização. In: ANTUNES, R. (org.). Riqueza e miséria do trabalho no Brasil II. São Paulo: Boitempo, 2013. p. 217-227. VERGER, A.; NORMAND, R. Nueva gestión pública y educación: elementos teóricos y conceptuales para el estudio de un modelo de reforma educativa global. Educação \& Sociedade Campinas, v. 36, n. 132, p. 573-840, set. 2015. http://doi.org/10.1590/ ES0101-73302015152799

\section{SOBRE OS AUTORES}

Elydimara Durso dos Reis é mestranda em educação pela Universidade de São Paulo (USP).

E-mail: elydimara.reis@usp.br

Carmen Sylvia Vidigal Moraes é doutora em sociologia pela Universidade de São Paulo (USP). Professora da mesma instituição.

E-mail: moraescs@usp.br

Felipe Alencar é mestrando em educação pela Universidade de São Paulo (USP). Pedagogo da Universidade Federal do ABC (UFABC).

E-mail: felipealencar@usp.br 
Conflitos de interesse: Os autores declaram que não possuem nenhum interesse comercial ou associativo que represente conflito de interesses em relação ao manuscrito.

Financiamento: A pesquisa contou com o apoio do Conselho Nacional de Desenvolvimento Científico e Tecnológico (CNPQ) pela bolsa de mestrado concedida a uma das autoras (Elydimara Reis) e da Fundação de Amparo à Pesquisa do Estado de São Paulo (FAPESP) por meio do processo n. 2018/09983-0 - Pesquisa Política Educacional na Rede Estadual Paulista (1995 a 2018), da qual decorre este estudo.

Contribuições dos autores: Administração do Projeto, Análise Formal, Conceituação, Curadoria de Dados, Escrita - Primeira Redação, Escrita - Revisão e Edição, Investigação, Metodologia: MORAES, C. S. V.; REIS, D. R.; ALENCAR, F.

Recebido em 5 de novembro de 2020 Aprovado em 9 de abril de 2021 